\title{
Reduction of Losses and Capacity Release of Distribution System by Distributed Production Systems of Combined Heat and Power by Graph Methods
}

\author{
Parsa Sedaghatmanesh ${ }^{1, ~}$, Mohammad Taghipour ${ }^{2}$ \\ ${ }^{1}$ Electrical Power Engineering, Islamic Azad University of Saveh, Markazi, Iran \\ ${ }^{2}$ Department of Industrial Engineering, Science \& Research Branch of Islamic Azad University, Tehran, Iran
}

Email address:

Parsa.sm.86@gmail.com (P. Sedaghatmanesh),mohamad.taghipour@srbiau.ac.ir (M. Taghipour)

\section{To cite this article:}

Parsa Sedaghatmanesh, Mohammad Taghipour. Reduction of Losses and Capacity Release of Distribution System by Distributed Production Systems of Combined Heat and Power by Graph Methods. American Journal of Electrical Power and Energy Systems.

Vol. 4, No. 6, 2015, pp. 84-99. doi: 10.11648/j.epes.20150406.12

\begin{abstract}
Formulation of long term program of optimization of energy sector has positive effect on economy of country and improving the role of Iran in global energy markets. One of the results of optimization of energy supply sector is improvement of efficiency and reduction of environmental pollutants of energy generation. There are various optimization solutions in energy supply as combined power and heat generation at proper location of distribution network. This thesis is aimed to locate combined generation source via integrated graph algorithm with sensitivity analysis to reduce electric power loss and release capacity and increase economic productivity. The capacity is determined based on applying restrictions of voltage and available levels of candidate locations in the studied networks. The results of simulation are presented in standard 30-bus IEEE network to evaluate efficiency of the above method.
\end{abstract}

Keywords: Combined Generation System, Distribution Networks, Placement, Graph Algorithm, Sensitivity Analysis

\section{Introduction}

Now, due to economic issues, power plants are in big sizes with 150-1000 MW capacity. Indeed, such great power plant needs great economic investment, employees, space and strong and long transmission lines and this leads to increase of cost, design time, installation, operation and maintenance [1]. This great structure leads to vulnerability of system against natural events. Besides environmental problems, these issues increase the tendency to new generation methods. In distributed generation as called little generation at the point of consumption [2], applies distributed generators in distribution system to improve quality of power and eliminate technical problems. Some of the positive effects of DGs activity in network are as follows: Reduction of loss of lines, improvement of voltage profile, reduction of pollutant gases, increase of total return of energy, improving security and reliability of network, improvement of power quality, capacity release of distribution and transfer systems, delay of investment for network development, productivity improvement, reduction of treatment and health costs to reduce pollutants emission and increase of security in sensitive loads [3], [4]. In this study, combined heat and power/CHP connected to network is evaluated as one of DG technologies and their optimal place and capacity in radial distribution network can be determined by new method based on a combination of graph algorithm and sensitivity analysis and with the aim of reduction of losses of power and improvement of profile of voltage. Optimum state of network equipment with DG units is as besides fulfilling designer goals can be economical or they can have economic justification for energy suppliers. Based on high cost of installation and launching combined generation in CHP placement, the goal of minimizing costs is not acceptable. The capital return is similar at the worst and best state and it is better to investigate objective function except the cost. Thus, objective function of loss reduction and voltage profile modification are on priority of placement projects. The capacity of combined generation systems is computed based on the available levels of installation candidate locations in network and voltage restraint and finally placement and sizing algorithm is presented with definite goals of sample network: 30-bus IEEE standard and the results of studies are 
presented to evaluate the efficiency of above method. Normally, the required electricity of industrial units, commercial and residential buildings is supplied via the major power plants of our country. The thermal need of all of them is generated in the same site. Another method receiving much attention is combined heat and power generation as combined power and heat generation by a system. Thus, besides electric or mechanic power by the system, the loss heat of generator or engine is used as thermal energy. IN this system, the heat loss resources include emitting bases from initial place, cooling cycle and oil of lubrication and by putting thermal convertors, lost heat is recovered as heat.

Distributed/Dispersed Generation (DG) is an old idea referring to the end of $19^{\text {th }}$ century [1]. The required power plants are divided into three in terms of type of resources : Water (using energy of flowing water of river or water stored in reservoir of dams), thermal (using energy of fuels as oil, gas or coal) and nuclear (e.g. atomic energy) to the end of $20^{\text {th }}$ century, other generation technologies were unconventional.

Table 1-1 shows the share of each of above technologies in energy generation over the world to the recent century.

Generally, any technology of electric energy generation as combining in distribution system or it is connected to network via consumer of measurement device [5], can be called distributed generation. DG systems are introduced as modular systems [6] with capacity of less than 100 mvA [7] and less than 10MW [8]. It is predicted that in future, about $25 \%$ of new manufacturers of electric power in power networks are dedicated to distributed source [11].

Table 1. The share of different technologies in energy generation in $G W$ to the end of $20^{\text {th }}$ century [2].

\begin{tabular}{llllll}
\hline $\begin{array}{l}\text { Region } \\
\text { /Technology }\end{array}$ & Thermal & Water & Nuclear & $\begin{array}{l}\text { Others/ } \\
\text { Renewable }\end{array}$ & Total \\
\hline US & 642 & 176 & 109 & 18 & 945 \\
$\begin{array}{l}\text { Southern } \\
\text { America }\end{array}$ & 64 & 112 & 2 & 3 & 181 \\
$\begin{array}{l}\text { Western Europe } \\
\text { Eastern Europe }\end{array}$ & 353 & 142 & 128 & 10 & 633 \\
$\begin{array}{l}\text { and Russia } \\
\text { Middle East }\end{array}$ & 298 & 80 & 48 & 0 & 426 \\
$\begin{array}{l}\text { Africa } \\
\text { Asia and }\end{array}$ & 73 & 4 & 0 & 0 & 98 \\
$\begin{array}{l}\text { Oceania } \\
\text { Total }\end{array}$ & 651 & 160 & 69 & 4 & 95 \\
Percent & 2.175 & 694 & 358 & 35 & 884 \\
\hline
\end{tabular}

\section{Distributed Generation Technologies}

Distributed generators are divided into renewable and non-renewable (fossil fuel technologies) including these systems [2]:

Table 2. Different distributed generation generators [2].

\begin{tabular}{lll}
\hline Technology & Capacity range & Relationship with network \\
\hline Internal combustion engine & Hundreds of kilowatt to ten megawatts & synchron generator or AC/AC convertor \\
Combined cycle & Ten megawatt to hundreds of megawatts & \\
Combustion turbine & Some Megawatts to hundreds of Megawatts & synchron generator \\
Microturbine & Tens of kilowatts to some megawatts & AC/AC convertor \\
Fuel cell & Ten kilowatts to ten hundreds megawatts & DC/AC convertor \\
Wind & Some hundreds watts to some megawatts & Synchron generator \\
Solar, photolytic & Some watts to some hundreds of kilowatts & DC/AC convertor \\
Geothermal & Some hundreds of kilowatts to some megawatts & Synchron generator \\
Ocean & Some hundreds of kilowatts to some megawatts & 4-polar synchron generator \\
\hline
\end{tabular}

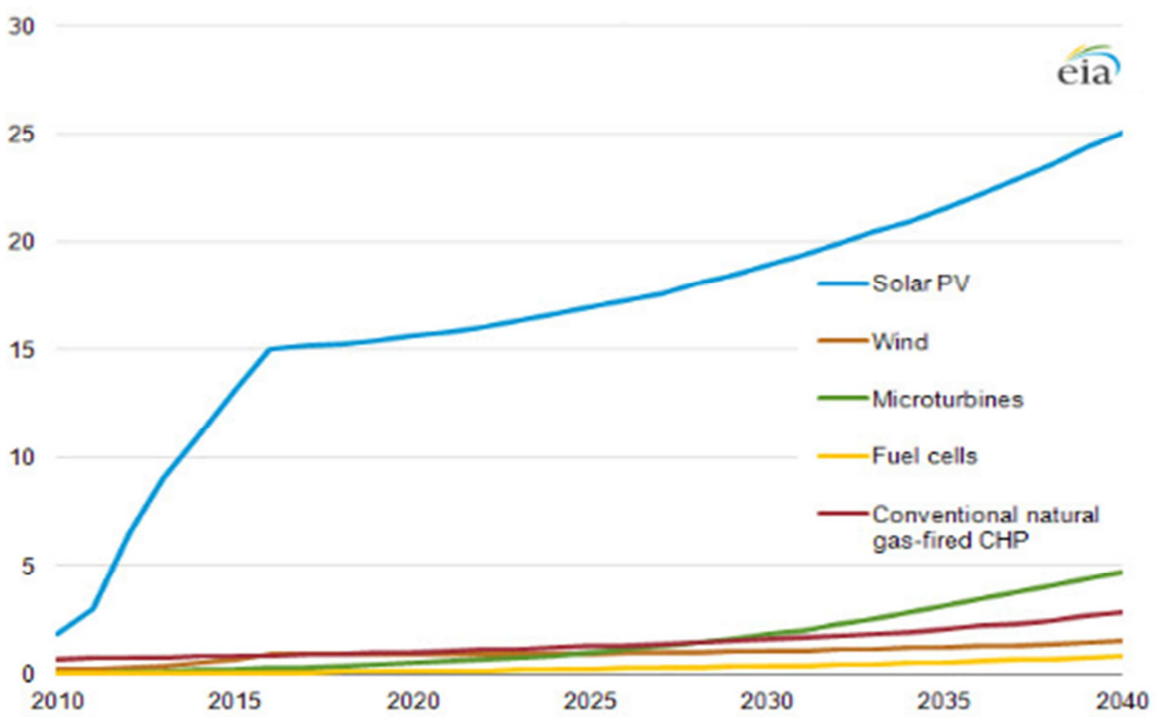

Figure 1. Estimation of energy generation by distributed generation resources $(G W)$. 
The share of distributed generation technologies in power generation market

DG share in electric energy generation is increased considerably as in the early 90s; Non- Utility Generators (NUGs) dedicate $5 \%$ of total generation in US. At the end of this decade, it reached $20 \%$ of total generation. In other words, it is increased from 40Gigawatt to more than 150 Gigawatts [2]. Fig 1 shows the annual increase of distributed generation capacity in Gigawatts from 2010 to 2040 [13].

Based on increasing utilities of DG generators in energy supply, future power networks are fed from various distributed resources making general power network and despite the complexity of power supply, the existence of a center as leadership of network and power control can be necessary.

\section{CHP and its Division Based on Technology of Incentives [16]}

CHP systems are based on separated components of initial incentive (thermal engine), heat recovery convertors and electric connections consider as a unified system. As the combined generation is based on power generation, these systems are classified based on its electric generator. The type of equipment providing the movement force of entire system determines the type of CHP system as including:

- Steam Turbine

- Gas Turbine

- Micro Turbine

- Reciprocating Engines
- fuel cell

Classification of CHP systems

Classification of CHP systems is defined in three levels and based on capacity of generated electric power as in following Table. We cannot consider this division as absolute.

Table 3. Classification of CHP based on capacity and use.

\begin{tabular}{lll}
\hline Use & Power range (kilowatt) & Capacity \\
\hline $\begin{array}{l}\text { Domestic-administrative } \\
\text { Administrative- }\end{array}$ & $1-100$ & Small/low \\
$\begin{array}{l}\text { Commercial-Industrial } \\
\text { Industrial }\end{array}$ & $100-10000$ & Average \\
\hline
\end{tabular}

The application and influence of project is based on required heat of the building in terms of qualitative and quantitative aspects. If hot water is required at low scale, commercial piston engines are the best choice. For each kilowatt/h energy, the heat of device can increase water temperature as 500 to $900 \mathrm{~kg} /{ }^{\circ} \mathrm{C}$. Water heating is one of the most common needs of all types of use and the difference is in quality and quantity. In case of the need to steam, turbines are the best choice. The need to heat to be used in ventilation systems is changed over the year and temperature changes. The best places to stabilize the domestic and administrative heat are those with low temperature changes over the year. Briefly, we can summarize the benefits and disadvantages of different CHP $s$ and their capacity in the following Table:

Table 4. Summary of CHP technology.

\begin{tabular}{|c|c|c|c|}
\hline $\begin{array}{l}\text { Type of } \\
\text { system }\end{array}$ & Benefits & Disadvantages & Existing capacities \\
\hline $\begin{array}{l}\text { Gas } \\
\text { Turbine }\end{array}$ & $\begin{array}{l}\text { High reliability } \\
\text { Low pollution } \\
\text { Heat with high quality } \\
\text { Without the need to condenser }\end{array}$ & $\begin{array}{l}\text { The high use of gas or gas compressor } \\
\text { Low return in case of production with low capacity } \\
\text { Reduction of generation with the increase of } \\
\text { temperature e }\end{array}$ & 500 kilowatts to $250 \mathrm{Mw}$ \\
\hline $\begin{array}{l}\text { Micro } \\
\text { turbines }\end{array}$ & $\begin{array}{l}\text { Low and small parts } \\
\text { Compressed size and low weight } \\
\text { Low air pollution and noise pollution } \\
\text { Without condenser } \\
\text { Long maintenance distance }\end{array}$ & $\begin{array}{l}\text { High investment cost } \\
\text { Low mechanic return } \\
\text { Limited to application at low temperature } \\
\text { Complexity of connection to electricity network }\end{array}$ & $30 \mathrm{kw}$ to $250 \mathrm{kw}$ \\
\hline $\begin{array}{l}\text { Piston } \\
\text { engines }\end{array}$ & $\begin{array}{l}\text { High efficiency } \\
\text { Flexibility in performance of a part of capacity } \\
\text { Rapid launching } \\
\text { Relative low investment cost } \\
\text { Being used as independent from network } \\
\text { Regulation of total generated load } \\
\text { Regulated at site with normal operators } \\
\text { Function with low pressure gas }\end{array}$ & $\begin{array}{l}\text { High maintenance cost } \\
\text { Limited to application at low temperature } \\
\text { Relatively high air pollution } \\
\text { It should be cold permanently; even output heat is } \\
\text { not used. } \\
\text { Noise pollution }\end{array}$ & $\begin{array}{l}\text { Spark ignition } \\
\text { For local consumption less than } \\
5 \mathrm{mw} \text {-with high speed } 1200 \text { lower } \\
\text { than } 4 \mathrm{mw} \\
\text { Compression ignition } \\
\text { Low speed } \\
\text { To } 75 \mathrm{mw}\end{array}$ \\
\hline $\begin{array}{l}\text { Steam } \\
\text { turbine }\end{array}$ & $\begin{array}{l}\text { Total high return } \\
\text { Variety of fuel } \\
\text { Heating more than one terminal } \\
\text { High reliability and life } \\
\text { The change in force to heat ratio }\end{array}$ & $\begin{array}{l}\text { Long launching } \\
\text { Low force to heat ratio }\end{array}$ & $50 \mathrm{kw}$ to $250 \mathrm{~mW}$ \\
\hline Fuel cell & $\begin{array}{l}\text { Low noise pollution } \\
\text { High return for various generated loads } \\
\text { Separated design }\end{array}$ & $\begin{array}{l}\text { High price } \\
\text { Low continuance and force density } \\
\text { The need to the process on fuel (except pure } \\
\text { hydrogen) }\end{array}$ & $5 \mathrm{kw}$ to $2 \mathrm{mw}$ \\
\hline
\end{tabular}




\section{Graph Algorithm}

Graph algorithm can create each of above algorithms as a part of itself and it is a general algorithm and by selection of a dimensional state compared to the present state is based on constraints and conditions and it is the most flexible algorithm against speed and precision change as the algorithm designer based on easy use of the rest of algorithms can make the speed or precision as dominant. Convergence in graph algorithm is an unavoidable issue as at the worst states, after long time, convergence is occurred, even if convergence is not found. In case of correct design of algorithm, graph algorithm can direct trial and error to the test of all states and this is a specific feature in all existing algorithms. Regarding the escape from relative optimal responses, graph algorithm is one of the strongest algorithms as easily by creating a loop in tree algorithm can escape from relative optimum value. This escape is unique among the algorithms and it is the best escape.

\subsection{Explanation of Graph Algorithm}

Here, we define the application of graph theory in optimization of an objective function and determination of optimum response. Assume that the system has the following state vector as $\mathrm{n}$ state $\mathrm{x} 1$ to $\mathrm{xn}$ :

$$
X=\left[X_{1}, \ldots, X_{n}\right]
$$

Also, objective function has the regulation

We try to find a trend to optimize F function determining optimum response as one of the states of $\mathrm{X}$ vector. In graph algorithm, we assume that we have $n$ vertices, each vertex refers to a definite state. The objective function in each state as the relevant vertex refers is called the weight of vertex. It means that if $n=3$, we achieve three vertices as: Inside each vertex, the referred state is mentioned and number of each vertex is written under it. Thus, we have:

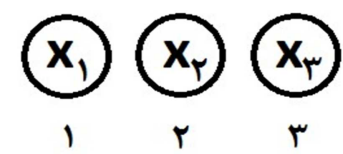

Figure 2. View of three vertices.

$$
X=\left[X_{1}, X_{2}, X_{3}\right]
$$

The equation of vertices weight vector:

$$
W=\left[W_{1}, W_{2}, W_{3}\right]
$$

Indeed, optimal response is vertex or minimum weight, at ideal state, investigation of $\mathrm{n}$ states and finding the weight of $\mathrm{n}$ vertices can direct use to optimum response. The number of industrial system states is high and investigation of all of them requires much time and this leads to solutions with absolute precision. Absolute precision is completely exact responses. At first, we consider a state as initial state. The selection of initial state can be performed after a process on system. For example, in a system, strong relations between system parameters can be selected and this leads to initial state.

Rank 1 is given to the initial state. This value is called the index of number of replications and it is called rank and is denoted by $\mathrm{m}$. For example if ith state is selected as initial state, to find the next replication or next rank, we can move along (n-i) other vertices and investigate their algorithm.

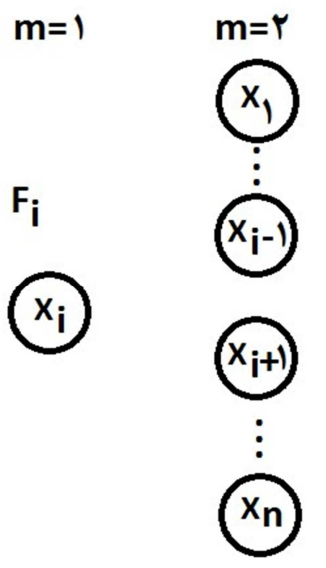

Figure 3. Ranking vertices of graph.

This method is the investigation of all states as timeconsuming. Thus, a solution should be thought to avoid the investigation of all states of rank 2. At first, some concepts are defined and the mentioned method is defined finally.

a. Edge: The line between two vertices and it exits if the difference of rank of two vertices is one.

b. Edge weight: Edge weight is zero or one. If edge weight is zero, dimension state is not investigated but if edge weight is one, the dimension state is investigated and objective function is evaluated.

After determining the weight of all mentioned edges between vertices rank 1 and vertex rank 1, objective function is considered one for rank two vertices connected to edges with weight 1 . If the weight of kth vertex is the lowest, the vertices of all states except $\mathrm{XK}$ is eliminated and is used in scale $m=3$.

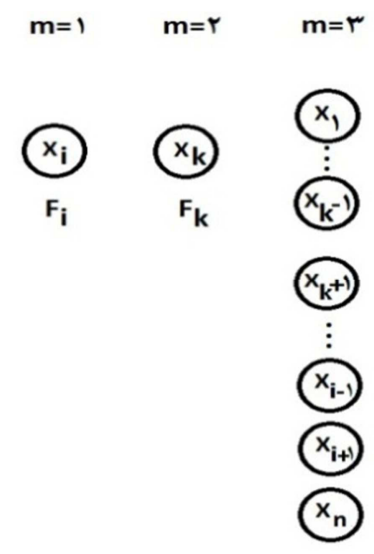

Figure 4. Formation, scale $m=3$ graph. 
Now we deal with $n-2$ vertices. As before, the edges are defined and weight of edges is determined. Then, the weight of vertices connected to edge is calculated with weight 1 or objective function of referred state and this trend is continued to convergence.

\subsection{Convergence Condition}

If the difference of weight of each vertex with the previous vertex is ignored, we achieve convergence and an optimum state is achieved and it is local or absolute. To escape from local optimas, a design is thought.

\subsection{Escaping from Local Optimas}

To escape from local optimas, we can use loop in in oriented graph algorithm. For example, Graph: $0(7)$ is considered.

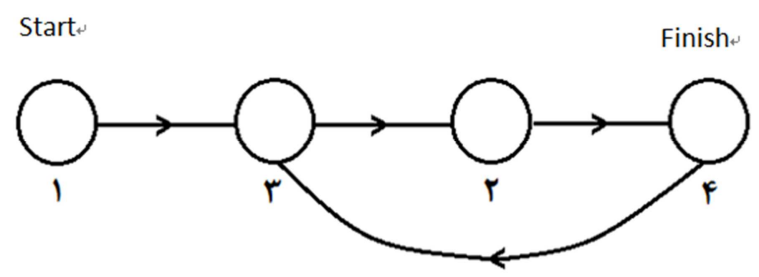

Figure 5. Graph algorithm with loop of escape from relative optimas.

In creation of this loop, we can return from final vertex to one of the previous vertices. If vertex 4 is not local optima, after vertex 3 , we go to vertex 2 , then vertex 4 . If vertex four is local optima, as the system is changed, from state 3 , we can go to another state. Selection of a vertex from algorithm path from which local optima to loop is created, it depends the function selected by the designer to escape from local optimas. This function is effective on changing responses close to absolute optima and it is one of the key functions of graph algorithm and based on its application is determined by algorithm designer. The mentioned function is called mutation function.

\subsection{Algorithm Finish}

Decision in algorithm finish is dependent upon the view of designer and type of function and it is after some continuous convergences to a value.

\subsection{Conclusion}

As it was said, the designer of graph algorithm should determine the followings based on the type of graph algorithm application:

Identification and determining of various system states

Initial state: The stages of initial state are determined as suitable initial selection helps us in absolute optimal solution.

Edge discriminant function: The determination of this function is based on decision making regarding the selection of states and compromise between speed and precision.

Selection of mutation function to escape from local optima's Algorithm finishing method.

\section{Objective Functions in Placement of Combined Generation Systems in Distribution Network}

The experts and planners of distribution systems aim to use distributed generations namely combined generation resources, growth of economic indices and increase of satisfaction of consumers to reduce environment pollution, reduction of losses, and improvement of reliability and increase of power quality. The benefits of distributed generation are achieved if they are in proper place and optimal capacity in network. The optimal allocation and placement of distributed generation besides mentioned benefits have other benefits and they are not ignored. These benefits include improvement of profile of voltage of load points and placement of voltage of busses of network in allowable range and reduction of power from network feeders due to compensation of losses and compensation of a part of power of network load and this reduces stress on feeders of network namely in output feeders from distribution post of network and this increases life of equipment. The objective function in this study is to evaluate losses reduction of distribution system and improvement of network voltage profile. To evaluate the saving of using CHP in distribution network, installation cost of system is also considered in objective function and a combination of goals of loss reduction and minimum cost is used for the designer.

\subsection{Economic Saving}

If the dedicated capital to project of CHP application in distribution network is limited, capital return time is considered by experts of network and the cost of installation of CHP systems is used as one of the most effective factors on costs of placement project and establishment of devices is applied in objective function as minimizing of total cost function includes the difference of value of generated energy by combined generation generators from the sum of energy loss costs in year and establishment of combined generation generators is the goal of placement and capacity determination project. The objective function is considered as (4):

$$
\text { Cost }=\mathrm{CHP}_{C}+\mathrm{C}_{\text {loss }}-\mathrm{CHP}_{i}
$$

Where $\mathrm{CHP}_{\mathrm{C}}$ is installation cost of $\mathrm{CHP}$ and $\mathrm{C}_{\text {loss }}$ annual loss cost and $\mathrm{CHP}_{\mathrm{i}}$ is annual generation energy CHP. This function is cost function that is minimized and the most important factor is high cost of CHP. This cost is not compensated over a year with saving cost of loss reduction and annual generation energy. Also, combined generation is not established only to be used in the first year and its generation is considered in life service of system in economic evaluation. It is better to define another objective function as the number of years of capital return by which a comparison is made between life service of system and capital return period and economic aspect of purchase of CHP systems is investigated. The capital return function is introduced as (5). 


$$
Y=\frac{C H P_{C}}{C H P_{L}+\Delta I_{L}}
$$

Where, $\mathrm{Y}$ is the number of capital returns years, $\mathrm{C}$ is $\mathrm{CHP}_{\mathrm{C}}$ installation cost of $\mathrm{CHP}, \mathrm{CHP}_{\mathrm{L}}$ annual generation energy value $C H P$ and $\Delta I_{L}$ as the cost of compensated loss. This function should be minimized to do capital return at short period and profit of CHP placement is achieved earlier. The installation cost of CHP systems as it was said for per kilowatt generation capacity is averagely 2420dollars and price of per kilowatts hour electric energy in entire electricity network of Iran without subsidy is $0.1 \$$. In calculation of capital return period of each of (9-3) equations is generalized by mentioned values and (6) is achieved:

$$
Y=\frac{P_{C H P} \times \sum_{I=1}^{K} C H P_{i}}{\left(\sum_{i=1}^{k} C H P_{i}+\Delta L\right) \times P_{k w}}
$$

Where, $P_{C H P}$ is price of per kilowatt capacity of CHP system, $C H P_{i}$ capacity of combined generation system ith, $\mathrm{K}$ is the number of CHP systems in network, $P_{k w}$ is the value of per kilowatt hour electricity in network, $\Delta L$ is total compensated losses.

\subsection{Losses Reduction}

Losses reduction is followed via various methods as installation of generated generators including combined generation systems in distribution network. Among all possible states for configuration and capacity of CHP systems, optimal state is selected in terms of power loss value in network lines as the study result. This objective function is defined by (7):

$$
\text { Loss }=3 \sum_{i=1}^{N} \operatorname{Re}\left(V_{i} I_{i}^{*}\right)
$$

Where, $V_{i}, I_{i}$ are voltage and current of ith line of distribution network and $\mathrm{N}$ number of network lines.

\subsection{Modification of Voltage Profile}

Combined generation systems can be useful in modification of fluctuation and weakness of distribution network voltage. Based on this reality, the second objective function as considered in another stage of project studies is the deviation function of mean of busses voltage from nominal voltage $(\mathrm{Vb})$ in distribution network and is defined as:

$$
V=\sqrt{\frac{\sum_{i=1}^{M}\left(V_{i}-V_{b}\right)^{2}}{M}}
$$

Where $\mathrm{M}$ is number of busses, $V_{i}$ is bus ith voltage, $\mathrm{Vb}$ is voltage of basis of network.

By minimizing this function, we can achieve a condition for capacity and place of CHPs as optimal where busses voltage has the least difference with nominal value 1 p.u. If the goal is reaching voltage of all buses to definite limit, this condition is added beside objective function and when this condition is satisfied, CHP systems enter the network.

\section{Problem Solving of Determining Place and Optimal Capacity of Combined Generation Systems in Distribution Network}

After determining the conditions of distribution system, feasibility of CHP installation based on load type, installation site and introduction of objective functions in project, it is required to define the general trend of problem solving in the form of stages and steps of start to end to have accurate perception of total studies. The problem of placement and suitable capacity of systems is based on goals. The first step is placement as by graph algorithm with high speed in problem solving compared to most of common algorithms and methods [5], we try to determine placement of combined generation generators. In this algorithm, for each of studied scenarios, this question is raised which capacities of systems are required by designer and which combined generation systems should be placed. Thus, we enter sizing field and require the size of systems for placement scenario from sizing block. The result of this block depends upon the calculations of load distribution in sample network. Thus, we use load distribution block to respond the higher block of sizing and the response achieves placement block and place scenario is analyzed and the result is stored. Then, another scenario and then the best state are determined in terms of objective function. In explanation of project performance, we go from smaller block as load distribution to main block as placement of system and problem solving method is defined.

\subsection{Determination of Optimal Capacity of Combined Generation Systems in Distribution Networks}

In this section, by knowing the system installation location, its capacity is determined to achieve highest profit of CHP system and escape from disorder in network performance. One of the important features of network is voltage of busses as kept in the defined limit. CHP generation power control can avoid voltage excess in network. Generally, in CHP sizing, definite conditions are used:

a. Distribution networks are used as radial without loop and placement of CHP is limited to future networks.

b. Constraint of voltage excess is considered. Busses voltage is modified by injection of output power of CHP but voltage excess is not occurred. Thus, in sizing CHP systems, each time with load distribution, voltage of busses is checked and in case of voltage exiting from the defined range 0.01 lower or upper than 1 per unit, even if the losses show the minimum value, the state is eliminated from possible states that CHP installation doesn't make any problem in its performance.

c. The higher the power of CHP system, on condition with lack of violation of problem constraints, power losses are lower.

If maximum generation power of CHP is considered as Pmax and sum of load of other busses of CHP with local 
consumption of bus of CHP is considered as L, optimal power of CHP production in terms of objective function is called $\mathrm{P}_{\mathrm{opt}}$ and each step as determined by precision of problem solving is assumed as Ps and we achieve $\mathrm{P}_{\text {opt }}$ in which objective function is minimized. Flowchart 5 shows work trend.

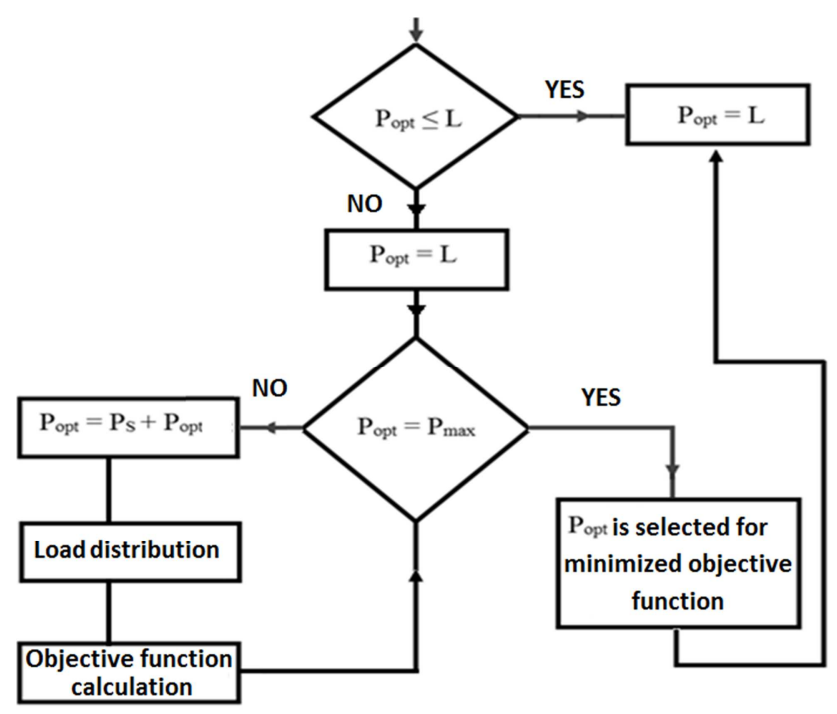

Figure 6. CHP sizing flowchart.

\subsection{Determining Optimal Location of Combined Generation Systems in Distribution Networks}

IN power system studies, if a state is selected among a series of initial states and the number of initial states are high, as all of them are not evaluated in terms of speed and memory, an algorithm is selected among various problem solving algorithms as genetics, neural networks, fuzzy, elimination and graph to define the movement between states based on proposed method of algorithm and without investigation of all of them, the best state is defined for designer.

Among various algorithms, graph algorithm has suitable speed and high efficiency in solving locating problems in power network [6]. This algorithm needs the definition of edge discriminant function as guiding the movement among various states. This study applies sensitivity analysis and sensitivity index in two types of studies of loss reduction and voltage profile modification as edge discriminant function of graph algorithm. Each movement is directed based on sensitivity and the effect of candidate bus to achieve the goal of reduction of losses and mean deviation of voltage to the next state.

\subsection{Sensitivity Analysis [7]}

In solving optimization problems, we are faced with two following methods [8]:

a. Objective function has soft trend guaranteeing the partial derivatives.

b. The equation system of objective function is solved as analytic
If $\mathrm{C}$ is objective function dependent upon $\mathrm{X} 1$, $\mathrm{Xa}$ variables, $\mathrm{C}=\mathrm{f}\left(\mathrm{X}_{1}, \ldots, \mathrm{X}_{\mathrm{a}}\right)$, we can define partial differential vector $\mathrm{n}$ variable $\mathrm{dx}$ and gradient vector as Equation 14:

$$
\nabla C=\left[\begin{array}{c}
\frac{\partial C}{\partial X_{1}} \\
\cdot \\
\cdot \\
\frac{\partial C}{\partial X_{n}}
\end{array}\right] d x \triangleq\left[\begin{array}{c}
d x_{1} \\
d x_{2} \\
\cdot \\
\cdot \\
\cdot \\
d x_{n}
\end{array}\right]
$$

General differential of objective function is as Equation (10):

$$
d C=\nabla C^{T} \cdot d x
$$

As the internal product of two vector is maximum that they are parallel, we can say if the changes are along the gradient vector, we have the highest change in objective function, we can present the following algorithm to search the optimal response:

The start point of $\mathrm{xn}$ is selected as well.

The gradient value is computed in that point and we take a differential step in that direction to achieve the next point. The previous stage is repeated as a good measure guarantees we approached adequate to optimal point. In placement of combined generation systems, like other optimization issues, step by step movements in problem solving algorithm are based on definite criterion as directing the movement to the defined destination. In placement among the candidate points of CHP installation, sensitivity index is a guidance from one step to another one and based on defined goals of problem, loss reduction and voltage profile modification, two indices of voltage sensitivity and losses are introduced by which the most sensitive candidate busses are selected in placement with the definite goals, the searching algorithm is started from those points and further selections are based on lower sensitivities.

\subsection{Sensitivity Index with the Goal of Reduction of Network Power Losses}

The main goal of placement of combined generation systems in distribution network is reduction of losses and release of capacity of distribution system. Thus, sensitivity index in losses reduction as called losses sensitivity index is used as guidance of directing in problem solving process. Losses sensitivity index is introduced with the Equation:

$$
L_{s}=\frac{\Delta \text { loss }}{\text { loss }}
$$

Where, $L_{s}$ is losses sensitivity index and $\Delta$ loss is the difference between the losses before and after installation of CHIP and loss, losses of network before CHP installation.

Sensitivity index is important in differential movement. Thus, a small part of CHP system (e.g. $1 \mathrm{kw}$ ) is added to the network without CHP and loss changes are evaluated. The sensitivity of each bus indicates its importance. Thus, for each bus, differential change in CHP capacity is applied from zero to small component and the effect in changes of network loss is evaluated. 


\subsection{Sensitivity Index with the Aim of Modification of Voltage of Network Buses}

Another goal of placement in this section is modification of voltage profile. Thus, sensitivity index is computed with the goal of voltage modification for each of busses and its value is defined in effect on voltage of network busses. The voltage sensitivity index is defined based on the mean of squares of changes of voltage of busses of network before and after installation of small part of CHP system as each time in a candidate bus.

$$
V_{S}=\sqrt{\frac{\sum_{i=1}^{a}\left(V_{i \text { with chp }}-V_{i \text { whit out chp }}\right)^{2}}{n}}
$$

Where, $V_{i \text { whit out chp }}, V_{i \text { with chp }}$ are bus ith voltage before and after installation of combined generation generator in one of the busses of network and $\mathrm{n}$ is the total number of busses.

\section{Searching Optimal Response by Graph Algorithm}

Now, we can discuss graph algorithm structure in placement solution of combined energy and heat systems. At first, we form a vector of elements of candidate points as $\mathrm{X}=\left[\mathrm{x}_{1}, \mathrm{X}_{2}, \ldots, \mathrm{X}_{\mathrm{n}}\right]$ in which $\mathrm{n}$ is the number of candidate points, $\mathrm{X}$ is state vector in which $\mathrm{x} 1 \mathrm{~s}$ are selection condition of candidate point ith. If it is one, it means the selection of the candidate point and zero indicates the lack of selection of candidate point. Thus, we have $2 \mathrm{n}$ state vector from zero to one and only one of them is optimal. Thus, we attribute a graph node to each of $2 n$ states and in each repetition from one node to another node, if these movements are directed, we are guided to response node. If each repetition is denoted by edge connecting two nodes, we achieve the graph showing repetition stages to response.

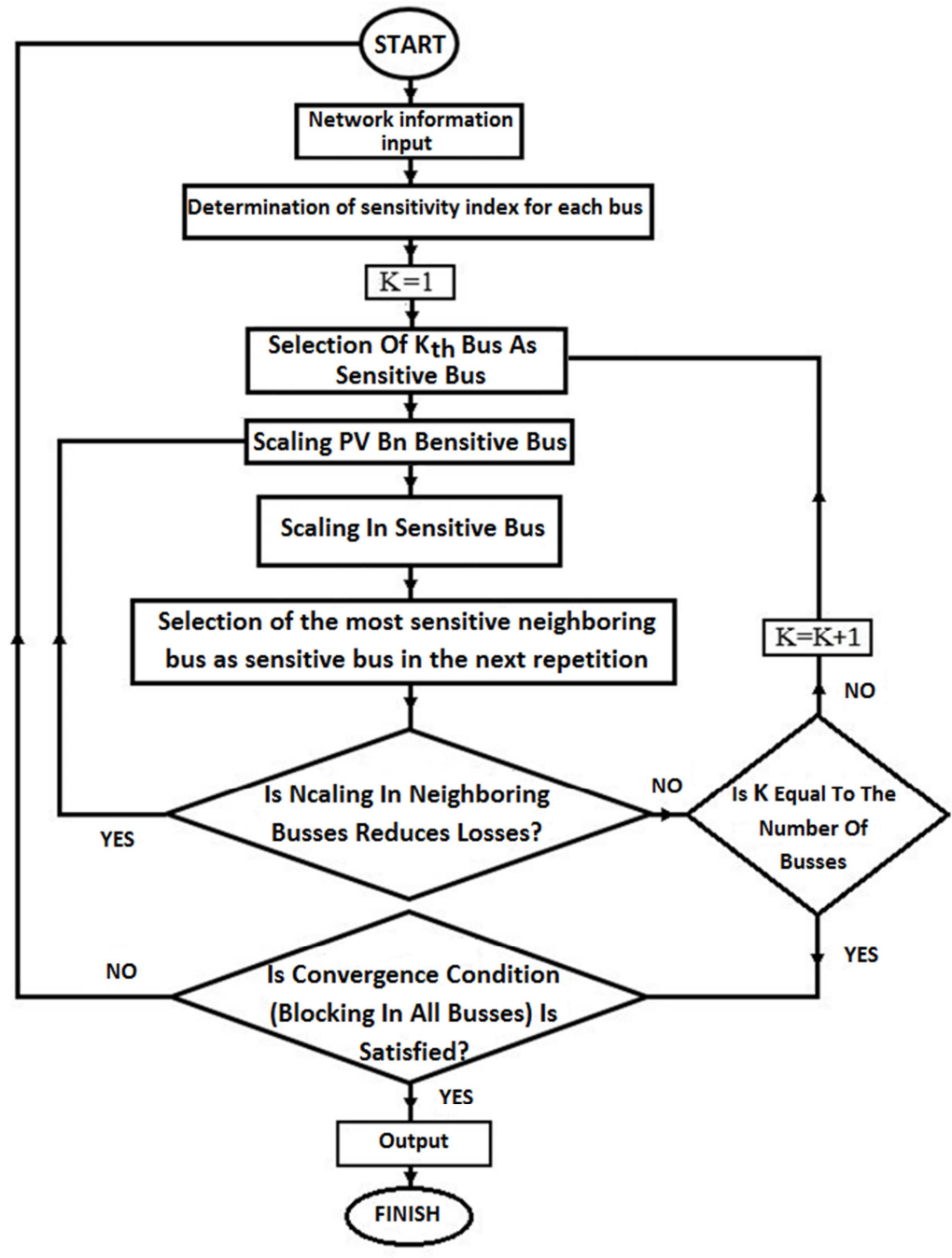

Figure 7. General flowchart of graph algorithm.

As it was said, to find optimal state vector, the following four stages are used:

a. Selection of initial state: In CHP placement, initial state to start algorithm is selected by analysis of sensitivity and defined sensitivity indices. b. Selection of edge discriminant function: According to graph. According to graph algorithm assumptions, movement of problem state in two continuous repetitions is as only CHP installation is change in one or two busses. The changes in this algorithm are limited 
to neighboring busses. Thus, edge discriminant function is selected as the most sensitive neighboring bus and to find the next state in one repetition by putting CHP in neighboring busses, we select the bus in which generator installation has the highest loss and we put CHIP in it.

c. Relative convergence condition: Convergence is occurred when the sensitivity of all buses is equal and by putting CHIP in neighboring busses, based on precision of problem solution, the losses of lines are not reduced compared to the previous state.

d. The loop of escape from local optima: To escape from local optimal, after convergence in an optima, we order the busses on priority, higher to less, the most valuable bus reducing losses is the start point of algorithm.

Flowchart of proposed method of locating combined generation systems in distribution networks

The results of studies in this study are presented in proposed method for placement of combined generation systems in distribution networks as shown briefly in Flowchart 7. The sizing block is observed in the body of algorithm and the load distribution block among the blocks is used repeatedly.

\section{Numerical Studies and Results of Analysis}

In this section, we evaluate the proposed algorithm and analysis of results of placement of CHP systems in distribution network. First, the functions of economic and electric goal including cost goal, capital return, losses and voltage are compared and the result is a good function for placement of CHP generators. Thus, the first stage of studies directs total project and main goal. In this section, 30-bus IEEE standard is investigated. Various researches have been conducted regarding the effect of two factors of capacity and installation place to achieve the required goals in this type of load distribution and it had also interesting results. The initial capital to purchase CHP system as one of the terms of capital return functions and costs is an exception in this regard and performance of system has no effect on its establishment cost. The calculations in first stage to study the objective functions are performed with optimistic view of equal generation with capacity or efficiency $100 \%$. The results showed that capital return period is higher than life service of combined generation systems. Thus, economic goals are outside of the list of followed goals in placement of combined generation generators in existing conditions. Thus, if efficiency is considered in two economic functions, better response is not achieved and capital return period is increased.

\subsection{The Study and Comparison of Four Objective Functions in Placement of Combined Generation Systems in Distribution Networks}

At first, 30-bus distribution networks are considered as sample network with fixed loads. CHP generators should be installed and used in feeders as commercial, administrative and industrial loads at peak time. In this thesis, CHP source is tested in load busses in network test. In this stage, as initial stage of placement studies of CHP systems, the network load is fixed. The goal of execution of this stage of studies is determining a suitable objective function. Selection is the best way.

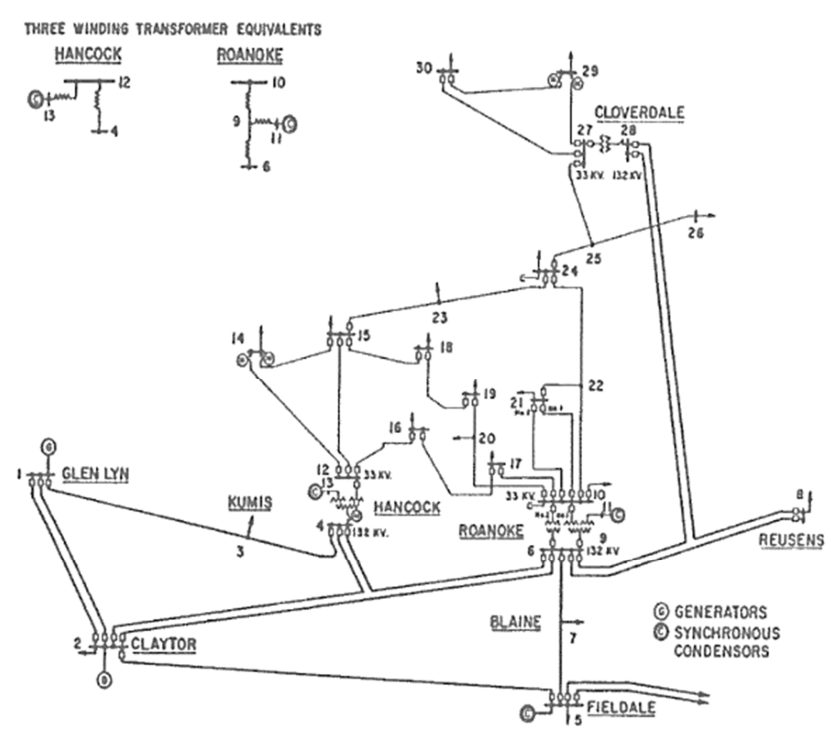

Figure 8. 30-bus distribution network IEEE.

\subsection{Features of Test Network}

Table 5. General features of test network.

\begin{tabular}{ll}
\hline General features of test network & \\
\hline Number of busses & 30 \\
Bus number PV & $2-5-8-11-13$ \\
Bus number PQ & 24 \\
Bus NO. SW & 1 \\
Number of lines & 41 \\
\hline
\end{tabular}

Table 6. Features of lines of test network.

\begin{tabular}{llllll}
\hline Line & From Bus & To Bus & R(p.u.) & X(p.u.) & Rating(p.u.) \\
\hline 1 & 1 & 2 & 0.0192 & 0.0575 & 0.0300 \\
2 & 1 & 3 & 0.0452 & 0.1852 & 0.0300 \\
3 & 2 & 4 & 0.0570 & 0.1737 & 0.0300 \\
4 & 3 & 4 & 0.0132 & 0.0379 & 0.0300 \\
5 & 2 & 5 & 0.0472 & 0.1983 & 0.0300 \\
6 & 2 & 6 & 0.0581 & 0.1763 & 0.0300 \\
7 & 4 & 6 & 0.0119 & 0.0414 & 0.0300 \\
8 & 5 & 7 & 0.0460 & 0.1160 & 0.0300 \\
9 & 6 & 7 & 0.0276 & 0.820 & 0.0300 \\
10 & 6 & 8 & 0.0120 & 0.420 & 0.0300 \\
11 & 6 & 9 & 0.0000 & 0.2080 & 0.0300 \\
12 & 6 & 10 & 0.0000 & 0.5560 & 0.0300 \\
13 & 9 & 10 & 0.0000 & 0.2000 & 0.0300 \\
14 & 9 & 11 & 0.0000 & 0.1100 & 0.0300 \\
15 & 4 & 12 & 0.0000 & 0.2560 & 0.0650 \\
16 & 12 & 13 & 0.0000 & 0.1400 & 0.0650 \\
17 & 12 & 14 & 0.1231 & 0.2559 & 0.0320 \\
18 & 12 & 15 & 0.0662 & 0.1304 & 0.0320 \\
\hline
\end{tabular}




\begin{tabular}{llllll}
\hline Line & From Bus & To Bus & R(p.u.) & X(p.u.) & Rating(p.u.) \\
\hline 19 & 12 & 16 & 0.0945 & 0.1987 & 0.0320 \\
20 & 14 & 15 & 0.2210 & 0.1997 & 0.0160 \\
21 & 16 & 17 & 0.0824 & 0.1932 & 0.0160 \\
22 & 15 & 18 & 0.1070 & 0.2185 & 0.0160 \\
23 & 18 & 19 & 0.0639 & 0.1292 & 0.0160 \\
24 & 19 & 20 & 0.0340 & 0.0680 & 0.0320 \\
25 & 10 & 20 & 0.0936 & 0.2090 & 0.0320 \\
26 & 10 & 17 & 0.0324 & 0.0845 & 0.0320 \\
27 & 10 & 21 & 0.0348 & 0.0749 & 0.0300 \\
28 & 10 & 22 & 0.0727 & 0.1499 & 0.0300 \\
29 & 21 & 22 & 0.0116 & 0.0236 & 0.0300 \\
30 & 15 & 23 & 0.1000 & 0.2020 & 0.0160 \\
\hline
\end{tabular}

\begin{tabular}{llllll}
\hline Line & From Bus & To Bus & R(p.u.) & X(p.u.) & Rating(p.u.) \\
\hline 31 & 22 & 24 & 0.1150 & 0.1790 & 0.0300 \\
32 & 23 & 25 & 0.1320 & 0.2700 & 0.0160 \\
33 & 24 & 25 & 0.1885 & 0.3292 & 0.0300 \\
34 & 25 & 26 & 0.2544 & 0.3800 & 0.0300 \\
35 & 25 & 27 & 0.1093 & 0.2087 & 0.0300 \\
36 & 28 & 27 & 0.0000 & 0.3960 & 0.0300 \\
37 & 27 & 29 & 0.2198 & 0.4153 & 0.0300 \\
38 & 27 & 30 & 0.3202 & 0.6027 & 0.0300 \\
39 & 29 & 30 & 0.2399 & 0.4533 & 0.0300 \\
40 & 8 & 28 & 0.0639 & 0.2000 & 0.0300 \\
41 & 6 & 28 & 0.0169 & 0.0599 & 0.0300 \\
\hline
\end{tabular}

Table 7. Voltage of test network.

\begin{tabular}{|c|c|c|c|c|c|c|c|c|c|c|c|c|c|c|c|}
\hline Bus & 1 & 2 & 3 & 4 & 5 & 6 & 7 & 8 & 9 & 10 & 11 & 12 & 13 & 14 & 15 \\
\hline Voltage(KV) & 132 & 132 & 132 & 132 & 132 & 132 & 132 & 132 & 33 & 33 & 11 & 33 & 11 & 33 & 33 \\
\hline LOAD (MW) & 0.0 & 21.7 & 2.4 & 67.6 & 34.2 & 0.0 & 22.8 & 30.0 & 0.0 & 5.8 & 0.0 & 11.2 & 0.0 & 6.2 & 8.2 \\
\hline Bus & 16 & 17 & 18 & 19 & 20 & 21 & 22 & 23 & 24 & 25 & 26 & 27 & 28 & 29 & 30 \\
\hline Voltage(KV) & 33 & 33 & 33 & 33 & 33 & 33 & 33 & 33 & 33 & 33 & 33 & 33 & 1322 & 33 & 33 \\
\hline LOAD (MW) & 3.5 & 9.5 & 3.2 & 9.5 & 2.2 & 17.5 & 0.0 & 3.2 & 8.7 & 0.0 & 3.5 & 0.0 & 0.0 & 2.4 & 10.6 \\
\hline
\end{tabular}

Table 8. The reactive power range of test network.

\begin{tabular}{|c|c|c|c|c|c|c|c|c|c|c|c|c|c|c|c|}
\hline Bus & 1 & 2 & 3 & 4 & 5 & 6 & 7 & 8 & 9 & 10 & 11 & 12 & 13 & 14 & 15 \\
\hline Q MIN(P.U) & -0.2 & -0.2 & & & -0.15 & & & -0.15 & & & -0.1 & & -0.15 & & \\
\hline Q MAX (P.U) & 0.0 & 0.2 & & & 0.15 & & & 0.15 & & & 0.1 & & 0.15 & & \\
\hline Bus & 16 & 17 & 18 & 19 & 20 & 21 & 22 & 23 & 24 & 25 & 26 & 27 & 28 & 29 & 30 \\
\hline Q MIN(P.U) & & -0.05 & 0.0 & & & & & -0.05 & & & & -0.05 & & & \\
\hline Q MAX (P.U) & & 0.05 & 0.055 & & & & & 0.055 & & & & 0.055 & & & \\
\hline
\end{tabular}

\subsection{Evaluation of Economic Objective Functions}

At first, economic goals are followed including cost objective and capital return. The defined cost function in (19) is based on 0.1 dollar for per $\mathrm{kWh}$ of electricity without using subsidy and 2420 dollars capita for each $\mathrm{kW}$ capacity of combined generation and (12) is achieved.

$$
\cos t=2420 * \sum \operatorname{ch} p+0.1 *\left(\text { loss }-\sum \operatorname{ch} p\right)
$$

$\sum \mathrm{CHP}$ is the sum of CHP capacities in network and loss electric loss of distribution network. Another economic objective function is capital return as with high meaning compared to cost function as cost function puts reduction of losses of system in a year beside great capacity to purchase CHP. Thus, CHP generation capital return in continuous years and loss reduction is compared with initial capital and required duration to achieve CHP income is computed to the maximum dedicated cost. Inflation rate is not considered for each of investment costs and generated electricity value and reduced losses and value of money is fixed and based on defined equation (10), capital return is shown in (14).

$$
\left.Y=\frac{\sum C H P * 2420 * 10^{6}}{0.1 *\left(\sum C H P+\left(L_{O S S} W O / \text { chp }^{-L O S S} W / C H P\right)\right.}\right)
$$

Where, $\Sigma$ CHP is the sum of CHP capacities installed in network in the studied state and $\operatorname{LOSS}_{(W / C H P)}$ is electric losses of network and LOSS $W O / c h p$ is losses at base state without installation of CHP in distribution network.

\subsection{Evaluation of Electric Objective Functions}

Second view is electric one and two objective functions of loss and voltage profile can be included. Loss objective function is defined with (15) and minimizing active power loss is the goal following by this function. Voltage profile objective function is observed in (16), the mean of deviation of busses voltage is shown from ideal voltage of network $\left(\mathrm{V}_{\mathrm{i}-} \mathrm{V}_{\mathrm{b}}\right)$ :

$$
\begin{array}{r}
L O S S=\sum_{i=1}^{N} \operatorname{Re}\left(V_{i} I_{i}^{*}\right) \\
V=\sqrt{\frac{\sum_{i=1}^{M}\left(V_{i}-V_{b}\right)^{2}}{M}}
\end{array}
$$

Where, $\mathrm{V}_{\mathrm{i}}$ is bus ith voltage in the studied state, $\mathrm{N}$ is the number of busses; $\mathrm{M}$ is the number of lines of network.

\subsection{The Results of Objective Function Evaluation}

To compare simulation state, without and with CHP, at first load distribution is done in the studied network and basic electric losses are computed and then placement is done with the minimizing goal of objective functions.

\subsection{Placement with the Goal of Minimizing Power Loss Function and Voltage Profile}

\subsubsection{The Evaluation of Power Losses}

At first, by load distribution in test network, power losses 
are achieved. These losses are shown on graph network in Figure 9 as weight of each line.

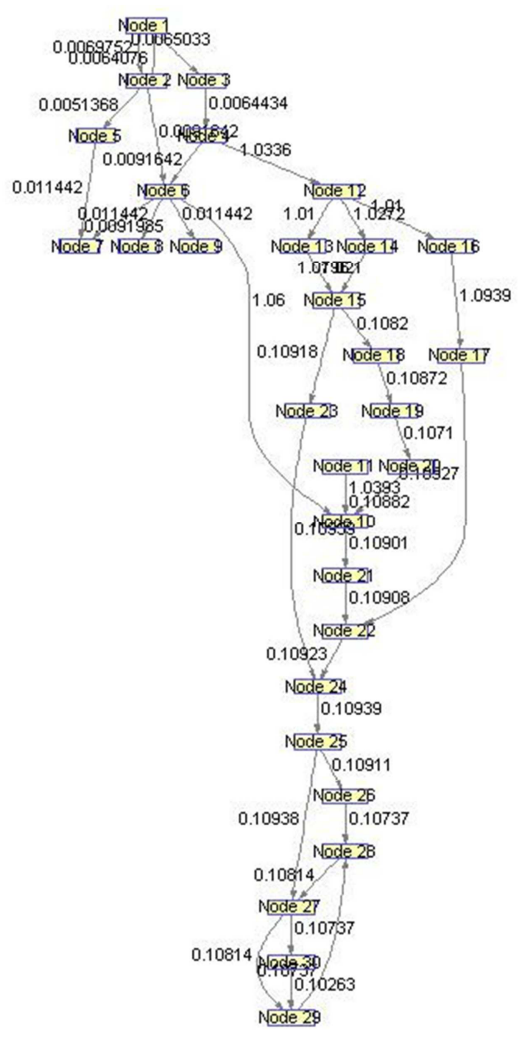

Figure 9. Graph of power losses in entire test network in each line.

Figure 10 shows the lines with highest losses in mw.

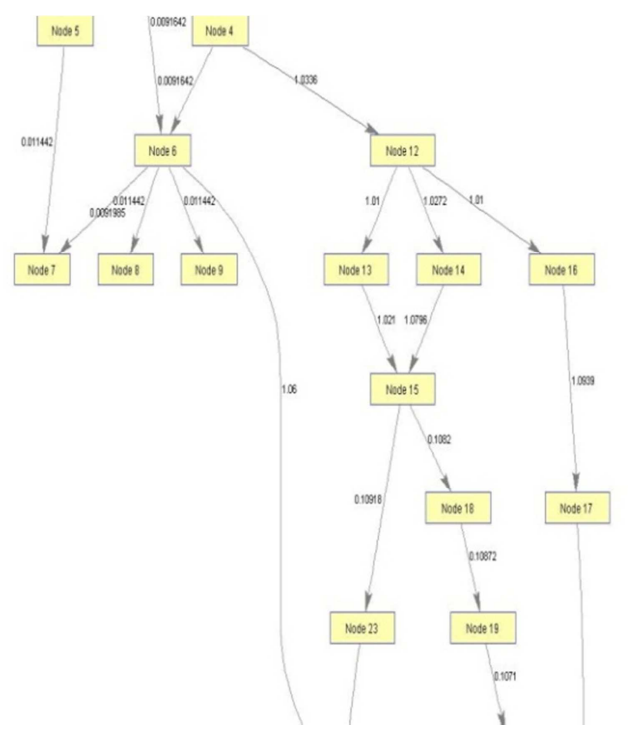

Figure 10. Graph of power loss in a part of test network.

The sum of power losses in entire test network without CHP is $11.23 \mathrm{MW}$.

\subsubsection{The Evaluation of Voltage Profile}

At first, by load distribution in test network, voltage profile is achieved. As shown in Figure 11, busses 21-30 show the highest voltage reduction in test network.

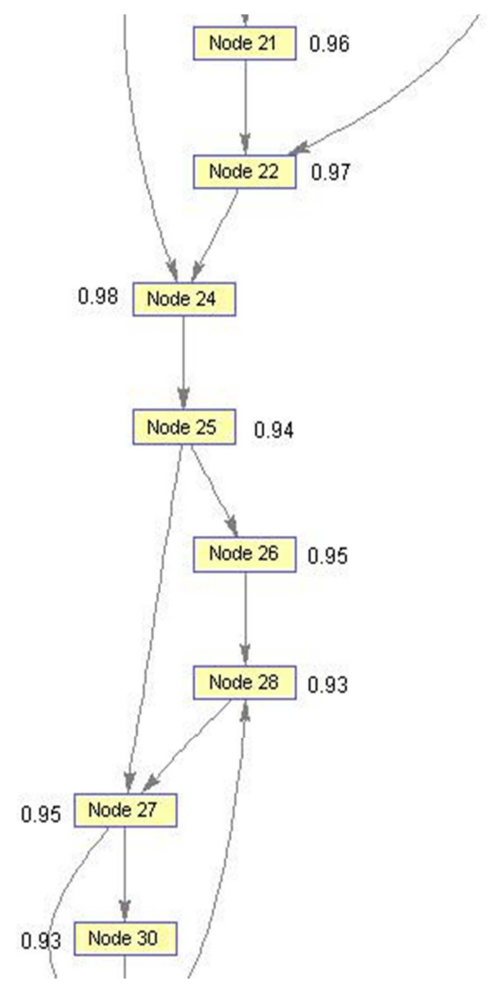

Figure 11. Graph of voltage size in some of busses of test network.

Table 9. Voltage of busses of test network.

\begin{tabular}{llll}
\hline Bus NO. & Bus voltage (p.u) & Bus No. & Bus voltage (p.u) \\
\hline 1 & 1.03 & 16 & 1.00 \\
2 & 1.03 & 17 & 0.93 \\
3 & 1.01 & 18 & 1.01 \\
4 & 0.97 & 19 & 1.02 \\
5 & 1.04 & 20 & 1.04 \\
6 & 1.01 & 21 & 0.96 \\
7 & 1.02 & 22 & 0.97 \\
8 & 1.01 & 23 & 1.00 \\
9 & 1.03 & 24 & 0.98 \\
10 & 1.02 & 25 & 0.94 \\
11 & 1.03 & 26 & 0.95 \\
12 & 1.02 & 27 & 0.95 \\
13 & 0.98 & 28 & 0.93 \\
14 & 1.00 & 29 & 0.93 \\
15 & 1.00 & 30 & 0.93 \\
\hline
\end{tabular}

\subsubsection{Putting CHP Source in Test Network}

To put CHP source in test network, at first by sensitivity analysis, we find a bus to have the lowest changes with the highest change in sum of electric power losses. Indeed, the goal of using sensitivity analysis is increasing convergence speed of graph algorithm. By this method, the best state of start is achieved.

\section{(i). Formation of Edge Discriminant Function Matrix}

To define the movement of CHP source among busses o network, as shown in Chapter 3, edge discriminant function is used and in neighbourhood of selected bus by sensitivity analysis can be applied. 
Table 10. Matrix of edge discriminant function

\begin{tabular}{|c|c|c|c|c|c|c|c|c|c|c|c|c|c|c|}
\hline 1 & 2 & 3 & 4 & 5 & 6 & 7 & 8 & 9 & 10 & 11 & 12 & 13 & 14 & 15 \\
\hline 0 & 1 & 1 & 0 & 0 & 0 & 0 & 0 & 0 & 0 & 0 & 0 & 0 & 0 & 0 \\
\hline 0 & 0 & 0 & 1 & 1 & 1 & 0 & 0 & 0 & 0 & 0 & 0 & 0 & 0 & 0 \\
\hline 0 & 0 & 0 & 1 & 0 & 0 & 0 & 0 & 0 & 0 & 0 & 0 & 0 & 0 & 0 \\
\hline 0 & 0 & 0 & 0 & 0 & 1 & 0 & 0 & 0 & 0 & 0 & 1 & 0 & 0 & 0 \\
\hline 0 & 0 & 0 & 0 & 0 & 0 & 1 & 0 & 0 & 0 & 0 & 0 & 0 & 0 & 0 \\
\hline 0 & 0 & 0 & 0 & 0 & 0 & 1 & 1 & 1 & 1 & 0 & 0 & 0 & 0 & 0 \\
\hline 0 & 0 & 0 & 0 & 0 & 0 & 0 & 0 & 0 & 0 & 0 & 0 & 0 & 0 & 0 \\
\hline 1 & 0 & 0 & 0 & 0 & 0 & 0 & 0 & 0 & 0 & 0 & 0 & 0 & 0 & 0 \\
\hline 0 & 0 & 0 & 0 & 0 & 0 & 0 & 0 & 0 & 0 & 0 & 0 & 0 & 0 & 0 \\
\hline 0 & 0 & 0 & 0 & 0 & 0 & 0 & 0 & 0 & 0 & 0 & 0 & 0 & 0 & 0 \\
\hline 0 & 0 & 1 & 0 & 0 & 0 & 0 & 1 & 0 & 0 & 0 & 0 & 0 & 0 & 0 \\
\hline 0 & 1 & 0 & 0 & 0 & 0 & 0 & 0 & 0 & 0 & 0 & 0 & 1 & 1 & 0 \\
\hline 0 & 0 & 0 & 0 & 0 & 0 & 0 & 0 & 0 & 0 & 0 & 0 & 0 & 0 & 0 \\
\hline 0 & 0 & 0 & 1 & 0 & 0 & 0 & 0 & 0 & 0 & 0 & 0 & 0 & 0 & 1 \\
\hline 0 & 0 & 0 & 0 & 1 & 0 & 0 & 0 & 0 & 0 & 0 & 0 & 0 & 0 & 0 \\
\hline 0 & 0 & 0 & 0 & 0 & 0 & 0 & 0 & 0 & 0 & 0 & 0 & 0 & 0 & 0 \\
\hline 0 & 0 & 0 & 0 & 0 & 0 & 1 & 0 & 0 & 0 & 0 & 0 & 0 & 0 & 0 \\
\hline 0 & 0 & 0 & 0 & 0 & 0 & 0 & 0 & 1 & 0 & 0 & 0 & 0 & 0 & 0 \\
\hline 0 & 0 & 0 & 0 & 0 & 0 & 0 & 0 & 0 & 0 & 0 & 0 & 0 & 0 & 0 \\
\hline 0 & 0 & 0 & 0 & 0 & 0 & 0 & 0 & 1 & 0 & 0 & 0 & 0 & 0 & 0 \\
\hline 0 & 0 & 0 & 0 & 0 & 0 & 0 & 0 & 0 & 1 & 0 & 0 & 0 & 0 & 0 \\
\hline 0 & 0 & 0 & 0 & 0 & 0 & 0 & 0 & 0 & 0 & 1 & 1 & 0 & 0 & 0 \\
\hline 0 & 0 & 0 & 0 & 0 & 0 & 0 & 0 & 0 & 0 & 0 & 0 & 0 & 0 & 0 \\
\hline 0 & 0 & 0 & 0 & 0 & 0 & 0 & 0 & 0 & 0 & 0 & 0 & 0 & 1 & 1 \\
\hline 0 & 0 & 0 & 0 & 0 & 0 & 0 & 0 & 0 & 0 & 0 & 1 & 0 & 0 & 0 \\
\hline 0 & 0 & 0 & 0 & 0 & 0 & 0 & 0 & 0 & 0 & 0 & 0 & 0 & 0 & 0 \\
\hline 0 & 0 & 0 & 0 & 0 & 0 & 0 & 0 & 0 & 0 & 0 & 0 & 0 & 0 & 0 \\
\hline 0 & 0 & 0 & 0 & 0 & 0 & 0 & 0 & 0 & 0 & 0 & 0 & 0 & 0 & 0 \\
\hline 0 & 0 & 0 & 0 & 0 & 0 & 0 & 0 & 0 & 0 & 0 & 0 & 0 & 0 & 0 \\
\hline
\end{tabular}

\begin{tabular}{|c|c|c|c|c|c|c|c|c|c|c|c|c|c|c|}
\hline 16 & 17 & 18 & 19 & 20 & 21 & 22 & 23 & 24 & 25 & 26 & 27 & 28 & 29 & 30 \\
\hline 0 & 0 & 0 & 0 & 0 & 0 & 0 & 0 & 0 & 0 & 0 & 0 & 0 & 0 & 0 \\
\hline 0 & 0 & 0 & 0 & 0 & 0 & 0 & 0 & 0 & 0 & 0 & 0 & 0 & 0 & 0 \\
\hline 0 & 0 & 0 & 0 & 0 & 0 & 0 & 0 & 0 & 0 & 0 & 0 & 0 & 0 & 0 \\
\hline 0 & 0 & 0 & 0 & 0 & 0 & 0 & 0 & 0 & 0 & 0 & 0 & 0 & 0 & 0 \\
\hline 0 & 0 & 0 & 0 & 0 & 0 & 0 & 0 & 0 & 0 & 0 & 0 & 0 & 0 & 0 \\
\hline 0 & 0 & 0 & 0 & 0 & 0 & 0 & 0 & 0 & 0 & 0 & 0 & 0 & 1 & 0 \\
\hline 0 & 0 & 0 & 0 & 0 & 0 & 0 & 0 & 0 & 0 & 0 & 0 & 0 & 0 & 0 \\
\hline 0 & 0 & 0 & 0 & 0 & 0 & 0 & 0 & 0 & 0 & 0 & 0 & 1 & 0 & 0 \\
\hline 0 & 0 & 0 & 0 & 0 & 0 & 0 & 0 & 0 & 0 & 0 & 0 & 0 & 0 & 0 \\
\hline 0 & 1 & 0 & 0 & 1 & 1 & 1 & 0 & 0 & 0 & 0 & 0 & 0 & 0 & 0 \\
\hline 0 & 0 & 0 & 0 & 0 & 0 & 0 & 0 & 0 & 0 & 0 & 0 & 1 & 1 & 0 \\
\hline 0 & 0 & 0 & 0 & 0 & 0 & 0 & 0 & 0 & 0 & 0 & 0 & 0 & 0 & 0 \\
\hline 0 & 0 & 0 & 0 & 0 & 0 & 0 & 0 & 0 & 0 & 0 & 0 & 0 & 0 & 1 \\
\hline 0 & 0 & 0 & 0 & 0 & 0 & 0 & 0 & 0 & 0 & 0 & 0 & 0 & 0 & 0 \\
\hline 0 & 0 & 0 & 0 & 0 & 0 & 0 & 0 & 0 & 0 & 0 & 0 & 0 & 0 & 0 \\
\hline 0 & 0 & 0 & 0 & 0 & 0 & 0 & 0 & 0 & 0 & 0 & 0 & 0 & 0 & 0 \\
\hline 0 & 0 & 0 & 0 & 0 & 0 & 0 & 0 & 0 & 0 & 0 & 0 & 0 & 0 & 0 \\
\hline 0 & 0 & 0 & 0 & 0 & 0 & 0 & 0 & 0 & 0 & 0 & 0 & 0 & 0 & 0 \\
\hline 0 & 0 & 0 & 0 & 0 & 0 & 0 & 0 & 0 & 0 & 0 & 0 & 0 & 0 & 0 \\
\hline 0 & 0 & 0 & 0 & 0 & 0 & 0 & 0 & 0 & 0 & 0 & 0 & 0 & 0 & 0 \\
\hline 0 & 0 & 0 & 0 & 0 & 0 & 0 & 0 & 0 & 0 & 0 & 0 & 0 & 0 & 0 \\
\hline 0 & 0 & 0 & 0 & 0 & 0 & 0 & 0 & 0 & 0 & 0 & 0 & 0 & 0 & 0 \\
\hline 0 & 0 & 0 & 0 & 0 & 0 & 0 & 0 & 0 & 0 & 0 & 0 & 0 & 0 & 1 \\
\hline 0 & 0 & 0 & 0 & 0 & 0 & 0 & 0 & 0 & 0 & 0 & 0 & 0 & 0 & 0 \\
\hline 0 & 0 & 0 & 0 & 0 & 0 & 0 & 0 & 0 & 0 & 0 & 0 & 0 & 0 & \\
\hline 0 & 0 & 0 & 0 & 0 & 0 & 0 & 1 & 0 & 0 & 0 & 0 & 0 & 0 & 0 \\
\hline 0 & 0 & 0 & 1 & 0 & 1 & 0 & 0 & 0 & 0 & 0 & 0 & 0 & 0 & \\
\hline 0 & 0 & 0 & 0 & 1 & 0 & 0 & 0 & 0 & 0 & 1 & 0 & 0 & 0 & 0 \\
\hline
\end{tabular}

Graphic chart of edge Discriminant and CHP movement in neighboring busses 


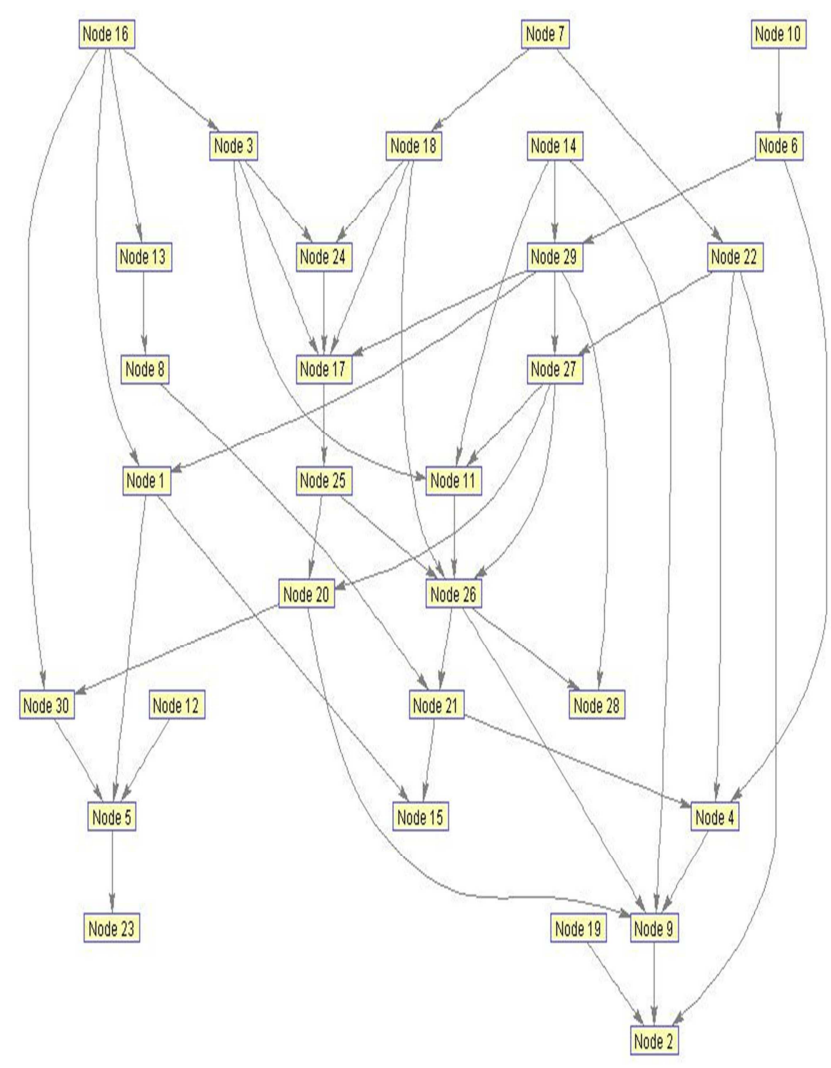

Figure 12. Graphic view of edge discriminant.

Graphic chart of Figure 13 shows a path in test network with the lowest changes in size of losses and profile of voltage. In this path, graph algorithm achieves convergence. This path includes busses 21, 22, 24, 25 .

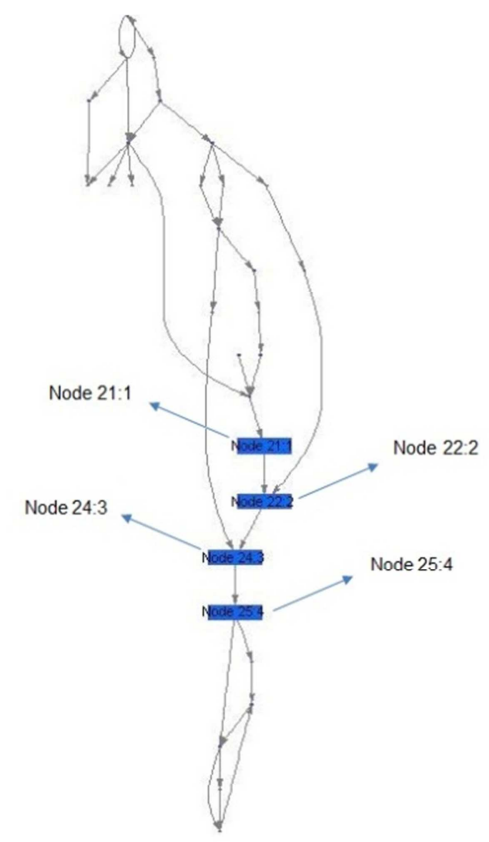

Figure 13. Convergence path based on sensitivity analysis.

\section{(ii). CHP Installation Site and Its Capacity}

Among 4 busses with numbers 21, 22, 24, 25 busses. NO. 25 is with capacity $2.14 \mathrm{Mw}$.

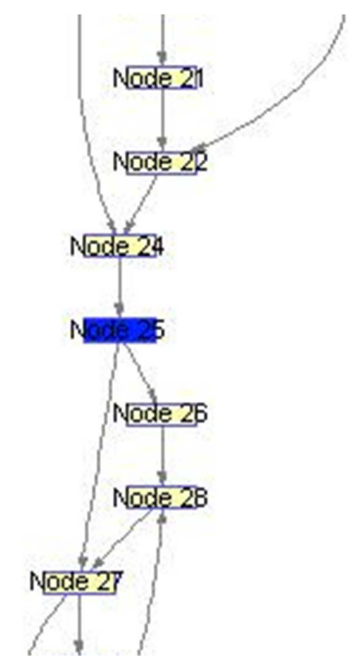

Figure 14. CHP installation site

\subsection{Changes of Power Loss after CHP Installation}

The sum of power losses in entire test network in CHP installation time is $7.24 \mathrm{mw}$. In (31), the change of power losses is shown in some high loss lines of test network.

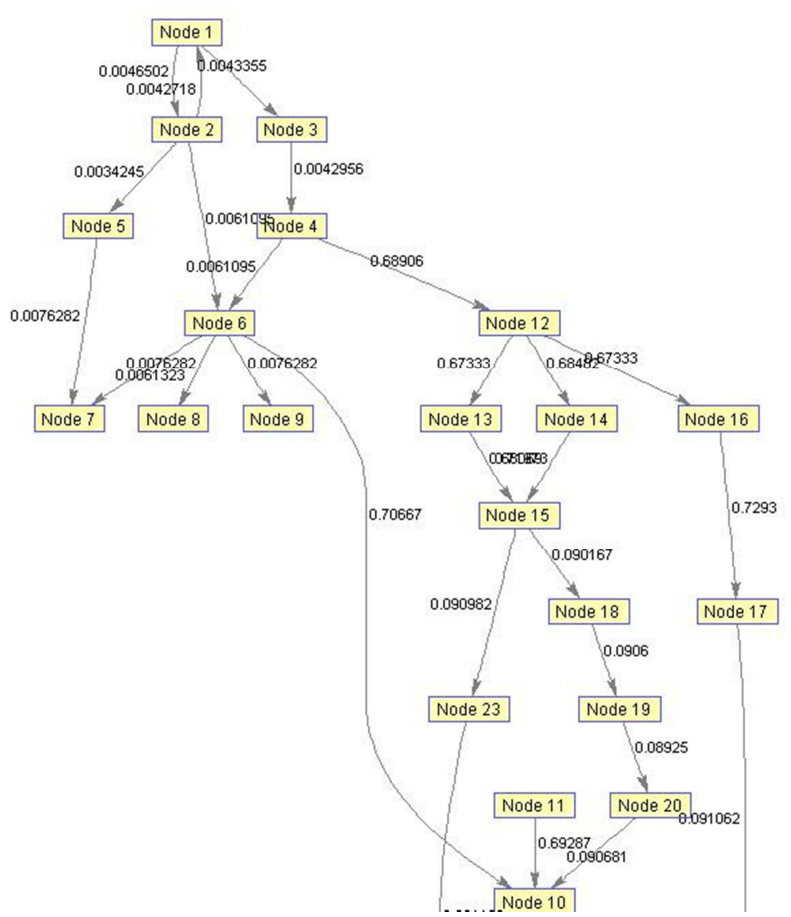

Figure 15. The power losses in test network in case of CHP source installation.

\subsection{The Changes of Voltage Profile in Test Network}

In 16 values of changes in voltage size after CHP installation in some busses, we can say the voltage size is improved in these busses. 


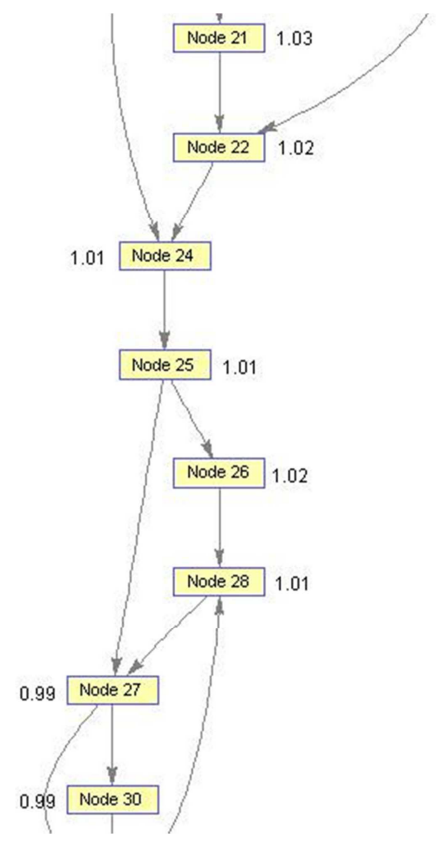

Figure 16. The profile changes of voltage after CHP installation.

Table 11. The changes of voltage profile after CHP installation.

\begin{tabular}{llll}
\hline Bus NO. & Bus voltage (p.u) & Bus No. & Bus voltage (p.u) \\
\hline 1 & 1.03 & 16 & 1.01 \\
2 & 1.03 & 17 & 0.95 \\
3 & 1.01 & 18 & 1.01 \\
4 & 0.98 & 19 & 1.03 \\
5 & 1.04 & 20 & 1.05 \\
6 & 1.01 & 21 & 1.03 \\
7 & 1.02 & 22 & 1.02 \\
8 & 1.01 & 23 & 0.99 \\
9 & 1.01 & 24 & 1.01 \\
10 & 1.01 & 25 & 1.01 \\
11 & 1.02 & 26 & 1.02 \\
12 & 1.01 & 27 & 0.99 \\
13 & 0.97 & 28 & 1.01 \\
14 & 1.00 & 29 & 0.99 \\
15 & 0.98 & 30 & 0.99 \\
\hline
\end{tabular}

\subsection{The Evaluation of Placement with the Goal of Minimizing Capital Return Function}

Placement is considered with the aim of minimizing capital return function, installation of a CHP system with capacity $2.23 \mathrm{mw}$ in bus- 25 as the best state with 34.34 years of capital return and the number of capital return years is almost 34. It can be said that putting local power plants in busses with high sensitivity to the generators with the aim of reduction of losses has short capital return. By analysis of gradient, we can say the most sensitive non-ending bus to capital return is bus 25 and in placement analysis with graph algorithm, the same bus is selected as a proper site to install CHP generator. It can be said that in none of above analyses in optimization of network from electric aspects, no considerable success is achieved. Under these conditions, placement with economic goal is not useful. The life service of combined generation systems is estimated as about 15-20 years. The capital return in the best state for our studied network is more than 34 years and the revenue of CHP systems are not equal with the initial capital. Indeed, this condition is the result of some realities in country. Electric energy is not valuable compared to other economic goods and investment to generate non-utility energy is not economical and combined generation technology is achieved of other industrial countries and combined generation system costs are high in our country due to its non-local nature. In addition, renewable systems don't have spiritual and materialistic support in country. Thus, when combined generation technology is not localized by internal experts, or suitable rules are not executed to support combined generation industry of energy and non-utility electricity generation as distributed units by policy makers, construction and operation cost from CHP systems is high as power generation is not economical and not accepted by capital owners.

Placement is achieved with electric goals with the aid of two objective functions of loss reduction and voltage modification in both cases and similar answer is achieved. For optimized reduction of loss and optimized increase of voltage range to good value, CHP generators are sized with highest capacity in all candidate busses. These losses are reduced as $0.36,41 \%$ and average voltage of buses is increased $1.74 \mathrm{v}$. The lowest voltage in buss no. 25 is increased from $382.724 \mathrm{v}$ at basic state to $385.748 \mathrm{v}$ in network equipped with CHP generator. The placement of CHP in distribution networks can reduce losses distribution considerably and this increases busses voltage range. By the calculations and results of load distribution in distribution networks, we can say placement of CHP systems in distribution network can reduce losses considerably and increase bus voltage range. CHP generators with low production for occupied area are suitable for distribution networks and can be used in weak pressure levels. The price of CHP system for each kw is very high as capital long-term return is achieved. Thus, CHP placement in distribution networks is not useful with economic analyses.

\section{Conclusion}

In this study, a new method is used for placement and optimal capacity of combined generation systems connected to utility with the aim of reduction of losses and release of capacity and modification of voltage profile in radial distribution networks. In placement of CHP systems, combined graph algorithm with sensitivity analysis is applied and their capacity is determined based on applying constraints of network voltage and available levels of candidate locations in the studied network. The simulation results are presented in sample network to support efficiency of above method.

The numerical study section of this project is full of various analytic studies with valuable results. 30-bus IEEE network as sample network is studied to prove efficiency of proposed method in placement of combined generation 
systems in distribution network with the goal of reduction of losses and modification of voltage profile and the results show the accuracy of placement by combination of graph algorithm with sensitivity analysis. Finally, these studies in addition of providing accuracy of proposed method in locating CHP systems show the benefits of using CHP generators in distribution network in terms of reduction of losses and improvement of voltage of network and shows a new way to cope up with the problems of distribution networks for operation from distributed systems namely energy generators with renewable source and combined generation generators for designers and planners of power network. Also, it proposes that we should actualize the new thoughts to avoid energy crisis or destruction of human environment.

\section{References}

[1] Philipson L., Willis H. L., 1999. Understanding Electric Utilities and De-Regulation, Marcel Dekker, New York.

[2] Puttgen H. B., MacGregor P. R., Lambert F.C., 2003. Distributed Generation: Semantic Hype or The Dawn of a New Era, IEEE Trans. On Power and Energy, 1(1): 22-29.

[3] Brown R. E., 1996. Reliability Assessment and Design Optimization in Electric Power Distribution Systems, Ph.D. Dissertation, University of Washington, WA.

[4] Lamarre L., 1993, The Vision of Distributed Generation, EPRI Journal.

[5] Ackermann T., Knyazkin V., 2002, Interaction Between Distributed Generation and the Distribution Network: Operation Aspects In: Proc.Of the IEEE/PES T\&D Conference and Exhibition, vol. 2, Asia Pacific.

[6] Griffin T., Tomsovic K., Secrest D., Law A., 2000. Placement of Dispersed Generation Systems for Reduced Losses. In: Proc. of the $3^{\text {rd }}$ Annu. Hawaii Int. Conf. Systems Sciences, Maui, HI

[7] Hegazy Y. G, Salama M. A., Chikhani A. Y., 2003. Adequacy Assessment of Distributed Generation Systems Using Monte Carlo Simulation, IEEE Trans. On Power Systems.

[8] Brown R., Pan I., Feng X., Koudev K., 2001 Siting Distributed Generation to Defer T\& D Expansion. of the IEEE T\&D Conference.

[9] L. R. Mattison, "Technical Analysis of the Potential for Combined Heat and Power in Massachusett," University of Massachusetts Amhers, Massachusetts, May 2006.

[10] Devender Singh, R. K. Misra, and Deependra Singh, "Effect of load models in Distributed Generation planing," IEEE Transaction on Power system, vol. 22 no 4, Nov. 2007.

[11] Dugan, R.C., and McDermott, T.E., "Distributed generatio," IEEE Industry Applications Magazin, vol. 8. No 2, pp. 19-25, 2002.

[12] Ramakumar R., Chiradeja P., 2002, Distributed Generation and Renewable Energy Systems, of the Intersociety Energy Conversion Engineering Conference.
[13] U.D.o. Energy. Modeling Distributed Generation in the Buildings Sectors. Washington DC. 2013.

[14] R. R. Chiradeja P, An Approach to Quantify the Technical Benefits of Distributed Generation," IEEE Trans. on energy Conversion, vol. (4)19, 2004.

[15] Fraser P., 2002, the Economics of Distributed Generation, International Energy Agency, Energy Prices and Taxes.

[16] Complete guidance of heat and power combined generation. Ministry of energy. 2009. Productivity improvement and power and energy economy.

[17] Seyed Mehrdad Hosseini, Mohammad HOssein Javidi. 2011. Placement and sizing combined generation of heat and power by PSO algorithm.

[18] B. Zhao, C. X. Guo, B. R. Bai, and Y. J. Cao, An improved particle swarm optimization algorithm for unit commitment, Int. J. Elect. Power Energy Syst., 28, (September (7)), 2006, 482-490.

[19] C. C. Kuo. "A Novel Coding Scheme for Practical Economic Dispatch by Modified Particle Swarm Approach". IEEE Trans. Power Syst., vol. 23, no. 4, pp. 1825-1835, Nov. 2008.

[20] Holland J.H., 1975, Adaptation in Natural and Artificial Systems, Ann Arbor, the University of Michigan Press, Michigan.

[21] Caire R., Retikre N., Morin N., Fontela M., Hadjsaid N., 2003, Voltage Management of Distributed Generation in Distribution Networks, IEEE.

[22] Celli G., Pilo F., 2001, Optimal Distributed Generation Allocation in MV Distribution Networks, pp. 81-86in Proc. of IEEE PICA Conf., Sydney, NSW, Australia.

[23] Willis H. L., Scott W. G., 2000, Distributed Power Generation, Marcel Dekker, New York.

[24] Willis H. L., 1997, Power Distribution Planning Reference Book, Marcel Dekker, New York.

[25] Carpinelli G., Celli G., Pilo F., Russo A., 2001, Distributed Generation Siting and Sizing Under Uncertainty, pp. 376401in Proc. IEEE Powertech Conf., vol. 4, Porto, Portugal.

[26] B, Defino, Modeling of the Integration of Distributed Generation into the Electrical System",IEEE Power Engineering Society Summer Meeting, vol 10, pp. 17.

[27] El-Khattam W., Hegazy Y., Salama M. M. A., 2005, An Integrated Distributed Generation Optimization Model for Distribution System Planning, IEEE Trans. On Power Systems, 20(2).

[28] El-Khattam W., Bhattacharya K., Hegazy Y., Salama M. M. A., 2004, Optimal Investment Planning for Distributed Generation in a Competitive Electricity Market, IEEE Trans. On Power Systems, 19(3).

[29] Derek W. A., Fletcher W., Fellhoelter K., 2003, Securing Critical Information and Communication Infrastructures through Electric Power Grid Independence, IEICE/IEEE INTELEC'03, pp: 19-23.

[30] Caisheng W., Nehrir, M.H., 2004, Analytical Approaches For Optimal Placement of Distributed Generation Sources in Power Systems, IEEE Trans. On Power Systems, 19(4): 2068 $-2076$. 
[31] Chang SK, Marks GE, Kato K (1990) optimal real-time voltage control. IEEE Trans. on Power Systems, vol 5, no 3, pp 750-756.

[32] Hollenstein W, Glavitch H (1990) Linear programming as a tool for treating constraints in a Newton OPF. Proceedings of the 10th Power Systems Computation Conference (PSCC), Graz, Austria, August 19-24.

[33] Karmarkar N (1984,) a new polynomial time algorithm for linear programming, Combinatorica 4, pp 373-395.

[34] Lu N, Unum MR (1993) Network constrained security control using an interior point algorithm. IEEE Transactions on Power Systems, vol 8, no 3, pp 1068-1076.

[35] Irisarri GD, Wang X, Tong J, Mokhtari S (1997) Maximum loadability of power systems using interior point nonlinear optimisation method. IEEE Trans. on Power Systems, vol 12, no 1 , pp 167-172.

[36] Wei H, Sasaki H, Yokoyama R (1998) an interior point nonlinear programming for optimal power flow problems within a novel data structure. IEEE Trans. on Power Systems, vol 13, no 3, pp 870-877.

[37] Torres GL, Quintana VH (1998) an interior point method for non-linear optimal power flow using voltage rectangular coordinates. IEEE Transactions on Power Systems, vol 13, no 4, pp 1211-1218.

[38] Zhang XP, Petoussis SG, Godfrey KR (2005) Novel nonlinear interior point optimal power flow (OPF) method based on current mismatch formulation. IEE Proceedings Generation, Transmission \& Distribution, to appear.

[39] El-Bakry S, Tapia RA, Tsuchiya T, Zhang Y (1996) On the formulation and theory of the Newton interior-point method for nonlinear programming. Journal of Optimisation Theory and Applications, vol 89, no 3, pp 507-541.

[40] Dashti R., Haghi, Qam. R., 2004. Re-configuraiton of distribution networks to reduce losses by graph theory. MA thesis. Tarbiat Modarres University. Tehran.

[41] Greatbanks J. A., PopoviC D. H., BegoviC M., Pregelj A., Green T. C., 2003, On Optimization for Security and Reliability of Power Systems with Distributed Generation, in Proc. Of IEEE Bologna PowerTech Conference, Bologna, Italy.

[42] Bayegan M., 2001, A Vision of The Future Grid, IEEE Power Eng. Review. 21:10-12. 